\title{
Interactive Whiteboard Use in High-Tech Science Classrooms: Patterns of Integration
}

\author{
http://dx.doi.org/10.3991/ijet.v9i9.4141 \\ R. Stroud, B. Drayton, K. Hobbs and J. Falk \\ TERC, Cambridge, MA, USA
}

\begin{abstract}
Interactive whiteboard (IWB) use has been associated with increased student motivation, engagement, and achievement, though many studies ignore the role of the teacher in effecting those positive changes. The current study followed the practice of 28 high school science teachers as they integrated the IWB into their regular classroom activities. The extent of teachers' adoption and integration fell along a continuum, from the technologically confident "early adopter" to the low-use "resistant adopter." Patterns of use are explored by extracting data from representative teachers' practice. Science-specific benefits of IWB use, barriers to integration, and lessons learned for professional development are discussed.
\end{abstract}

Index Terms - interactive whiteboard, technology adoption, technology integration, science teaching

\section{INTRODUCTION}

Interactive whiteboards (IWBs) are becoming standard technology in many elementary, secondary, and college classrooms across the globe. Integration of the IWB is highest in Europe (73\%), and also quite prevalent (between $35 \%$ and $50 \%$ ) in other countries including Denmark, Australia, and the United States [1]. Furthermore, research on technology trends suggests that these numbers will increase in the coming years [2]. Similar to the traditional whiteboard and projector set-up, teachers can use IWBs to project content to students. However, the new technology also opens up a host of additional possibilities. For example, the IWB enables teachers to save annotations, email them to students, and post them to their class website. Internet resources and files can be incorporated into lecture or discussion on the fly. Teachers and students can resize, rotate, zoom, and otherwise manipulate onscreen text and objects, and multiple students can interact with the board simultaneously, creating opportunities for student-centered instruction.

Considerable time and monetary investments in equipment, initial training, and continuing professional development are made based on the assumption that use of IWB technology in the classroom will improve student outcomes [3]. However, early research on the costs and benefits of IWB use tended to focus on the potential of the technology under favorable conditions, as part of targeted initiatives, with little focus on typical use by teachers with varying access to technology, technical support, and professional development experiences $[4,5,6]$.

What does IWB use look like in a typical high school science classroom? How is IWB use shaped by a teacher's attitudes towards technology? How, if at all, do teachers make use of the features of the IWB that set it apart from a traditional projector and whiteboard? We sought to build upon earlier work in the field and to address these questions by exploring the practice of 28 high school science teachers as they integrated the IWB into their regular classroom activities. We considered IWB integration along a continuum, from the most confident teachers to the most resistant. The influence of the IWB is explored with this range in mind, paying particular attention to ways in which it may improve science teaching and learning. Factors that may inhibit or promote full integration, both internal and external to the teacher, are also considered.

\section{A. Benefits of IWB Use: Initial Reports from the Field}

Initial investigations of IWB use in classrooms revealed two broad categories of benefits: enhancing teaching and supporting student learning [7]. In terms of enhancing teaching, one of the reported primary benefits is the efficient creation and delivery of flexible multimedia presentations $[6,7,8]$. Though teachers appreciate the ease with which they can create lessons, reports suggest that teachers do not often take advantage of the interactive features available via the IWB [6, 9]. Specifically, there is little evidence to suggest that teachers are encouraging students to directly manipulate the IWB. More often, the IWB is used exclusively by the teacher as a means to present their prepared lecture [5].

The potential for the IWB to support student learning has also been widely explored, with student motivation receiving significant attention. Teachers have reported that their students are more likely to participate in class discussion when the IWB was in use [8], and that it makes class more interesting, faster-paced, and exciting [4, 6]. Students have also indicated a preference for learning with the IWB $[4,10,11]$, frequently mentioning the integration of multimedia components into class lessons as a basis for their preference [7].

\section{B. More Recent Findings}

The preponderance of positive reviews, and the relative lack of negative ones, fueled new and continued investments in IWB technology. However, many of the early studies were "descriptive," "small scale," and reflective of the "enthusiasm of the 'initial innovator' or 'early adopter"' [12, p. 214]. Reported benefits were often not specific to the IWB, and could have been achieved using more traditional technology [12]. The more innovative features - the interactive features that set it apart from a traditional whiteboard described earlier - were often those that were least utilized.

More recent research on the utility of the IWB for teaching and learning has focused on integration in the 
PAPER

INTERACTIVE WhiteboARd USE IN High-TECH SCIENCE ClASSROOMS: PATTERNS OF INTEGRATION

context of particular subject areas $[13,14,15,16,17]$, and how the technology may transform learning in these domains. Science, in particular, is a subject in which active student participation and communication are essential, and where students must work together to posit and explore hypotheses, consider scientific concepts, and engage in meaning-making [18]. Research suggests that the IWB provides teachers and students with the opportunity to engage in these scientific activities in a way that transcends the possibilities available with traditional tools [19].

\section{Factors Affecting Technology Integration}

Though more and more classrooms are being equipped with IWBs, access to a new technology does not imply use $[12,20,21]$. Innovations may fail for a variety of reasons, including a lack of reliable technology and inadequate teacher training $[3,22,23]$. Well-trained technology staff can assist teachers when technology fails, though teachers must also have sufficient professional development experience with the tools so as to feel comfortable using them in their daily classroom activities. School culture, specifically the presence or absence of a supportive administration, is another factor that should be considered when evaluating teachers' adoption and integration of technology [24]. Teachers, even though with considerable skill in using technology, may feel stifled by a restrictive administration, while those same teachers, and even those with less comfort with technology, may thrive in a supportive environment.

Factors internal to the teacher also play a significant role [25]. Teachers work in a highly complex environment, where flexible knowledge is necessary to meet rapidly changing demands $[26,27]$. To be successful, teachers must have detailed knowledge of content and technology, the requisite pedagogical skill, and an understanding of the complex interplay between these factors $[25,28]$. Teachers, particularly new teachers, need effective training both in their specific content area and in the use of technology for teaching that content.

Furthermore, teachers need to feel confident using technology in order to use in a manner that enhances student learning [25]. Reference [29] reported that elementary and secondary teachers' beliefs regarding expectancy of success in using technology (e.g., agreeing with the statement that "using technology is not difficult, even though some students know more about computers than many teachers do") and their perceived value (e.g., "technology promotes student collaboration") of technology were significant predictors of the level of computer use in the classroom. However, reference [30] found that even tech savvy teachers, ranking high in both confidence and skill, were only "occasional practitioners" of communication technologies (p. 535), with $80 \%$ of teachers reporting using technology less than $50 \%$ of time. The authors reported barriers such as hardware issues, time constraints, and student skill level as possible impediments to technology integration.

Teachers cannot be expected to come in to the classroom with all of the required skills. High-quality professional development must be offered to teachers in order to provide them with the skills necessary to utilize technology in ways that are effective for student learning. Training should occur for pre-service teachers and be offered through teachers' careers as necessary.

\section{Current Study}

The current study examines patterns of IWB adoption and integration in the practice of 28 high school science teachers from six high-tech high schools. Teachers' use of the IWB was examined with respect to frequency of use, quality of use in terms of the ways in which it was used to support students' scientific understanding, and the extent to which it facilitated the integration of other software and technology. Based on these criteria, three distinct patterns of IWB use were identified: the "early adopter," the "typical user," and the "resistant adopter."

The primary research questions are as follows:

- How do science teachers vary in their adoption and integration of the IWB?

- How is this variation related to the benefits associated with IWB use in the science classroom?

- For the average or low-use teacher, what are the barriers to IWB integration?

- For the advanced IWB user, what factors enhance integration?

\section{METHOD}

\section{A. Participants}

The data reported is derived from a three-year study, "Researching Science in the Wireless High School," funded by the National Science Foundation (NSF/TPC grant \#0455795). Six schools, three public and three private, were selected to participate based on their commitment to providing students and teachers with cutting-edge technology. Each school had a ubiquitous computing environment where laptop computers, various other pieces of software and hardware, and Internet access were available throughout the school. Below is a brief description of each of the six schools (names of schools and personnel have been changed to preserve confidentiality) and a summary of teacher demographics.

School profiles: "Urban Tech High" is a public pilot school with approximately 300 students. Each classroom is equipped with an IWB. All students are issued a laptop upon entering 9th grade which becomes their own upon graduation; thus all laptops are replaced on a 4-year cycle. A laptop coordinator, network coordinator, and studentbased technology consulting company all contribute to the care and maintenance of the hardware infrastructure.

"Rural High" is a public high school that serves 419 students. The facility has wireless Internet access throughout and each classroom has a "tower" of 14 laptops. The school has a technical staff of three and the district has a three-year obsolescence plan for its school-owned laptops. All classrooms have interactive whiteboards with projectors.

"Private Academy" serves 360 students of which 80\% board. They have chosen not to install a wireless network but instead has installed 3,000 Ethernet drops around the campus. Classrooms have projectors, connected to the teacher's laptop; but only a few classrooms have an interactive white board. The school has a full-time technical staff of five.

"Large Urban High" serves 2,115 students in grades 9 through 12. Wireless Internet access is available via five mobile laptop carts that are wheeled throughout the school. Most classrooms have IWBs, though they are a 
new addition and many teachers have not yet integrated the technology in their teaching. The school does not have a technology coordinator.

"Small Private Religious" is a college-preparatory day school serving 290 students in grades 9-12. Students can access the Internet from any wireless-capable computer via wall-mounted wireless access points. Student laptop computers, available on mobile carts, employ external wireless cards. Each classroom has an IWB. There is an on-site technical support available to teachers and students.

"Small Private Day School" is a college-preparatory day school serving 395 students in grades 9-12. The school has ubiquitous wireless internet access. Two carts, each containing 18 student tablet (laptop) computers are available for teachers to check out. The school has on-site technical support, and laptops are on a three- to five-year replacement scheduled. Each classroom is equipped with an IWB.

Teacher profiles: Twenty-eight science high school science teachers across the six schools reported on the use of technology in their biology, earth science, physics and chemistry classes. The distribution of teachers from schools is as follows: five from Urban Tech High, three from Rural High, one from Private Academy, nine from Large Urban High, five from Small Private Religious, and five from Small Private Day School.

The majority of teachers were experienced, with four or more years of teaching at their current school (61\%), and the overwhelming majority of teachers reported feeling confident using technology (3\% "cautious," 38\% "comfortable," 44\% "adventurous," and 15\% "geek"). Teachers represented a wide range of age groups, with approximately $22 \%$ in their $20 \mathrm{~s}, 31 \%$ in their $30 \mathrm{~s}, 28 \%$ in their $40 \mathrm{~s}$, and $16 \%$ in their 50 s or older.

\section{B. Data Sources}

We used multiple data collection techniques in order to capture a detailed and comprehensive picture of teacher and student IWB use. Teacher logs were the primary data source, with supporting data provided by teacher questionnaires, classroom observations, focus groups, vignettes, and interviews with school leadership.

Teacher logs: Online teacher logs were developed in order to capture patterns of technology use across the academic year. Each teacher was asked to complete a biweekly online log detailing their use of ten tools: Word, Excel, PowerPoint, IWB, probeware, software, Internet, teacher's website, and Intranet. Teachers reported whether or not they or their students used the tools in the previous two-week period (yes/no), how often the tool was used (\# of classes), where it was used (in class, in the lab, or at home), for what purposes (class preparation, administration, communication, or demonstration/presentation), and the costs and benefits associated with use (open-ended). Frequency of IWB use over the course of the academic year was calculated as percentage of two-week log periods in which teachers reported using the tool at least once.

Teacher questionnaire: At the beginning of each academic year, all teachers completed a questionnaire regarding their background (e.g., years teaching), their comfort with and use of technology, and their professional development experience. Teachers also provided information on their case study classroom (e.g., number of students, content covered, etc.), and the nature of the technology available to them and to students. Response rates were high $(>90 \%)$ in all three years.

Classroom observations: Each classroom was observed twice per year by one or two trained observers. Observers were senior research staff with experience working in classrooms and conducting educational research. Observers used a structured observation protocol form to capture the flow of the class and the use of technology by both teacher and students. Observers noted the subject domain, context notes, notes regarding the flow of the lesson, science content and pedagogy, and technology use in 15minute increments. After the class period, observers filled out an "after the observation" section of the form with questions regarding classroom culture and pedagogy, technology use, and science content during the class. For observations where more than one observed visited the classroom, observers met afterwards to discuss the completed forms and resolve any areas of discrepancy.

Focus groups: Each year, focus groups were conducted [a] within schools and also [b] across schools within a subject area. [a] The within-school focus groups brought together all teachers from a single school in order to discuss school- and district-level issues that impacted their technology use. Through these meetings we obtained a more detailed look at school-level factors that encouraged and inhibited teachers' technology use and gained familiarity with the different teachers and their perspectives regarding technology use in the classroom.

[b] Teachers of each subject area (chemistry, biology, and physics) from across schools were also invited to travel to a neutral meeting place. In these targeted meetings, teachers were able to share ideas with others in their field. Researchers asked questions designed to highlight how teachers in a particular discipline use technology, what tools they choose to use and why, and what problems they face in the classroom that might be ameliorated with the help of new tools. Feedback suggested that these focus groups were particularly useful to teachers because it gave them the opportunity to meet with colleagues they might otherwise not have access to.

Vignettes: Teachers were asked to submit two vignettes of their practice per year, reflecting on their use of technology in a lesson or series of lessons. Guidelines were purposefully vague so that teachers felt free to choose the topic and how to present it. Vignettes described both positive and negative aspects of technology, the influence on students, and ways in which they might improve their practice in the future.

Interviews: Individual conversations with principals and technology coordinators provided information about the school context and culture, including availability of professional development opportunities and shared attitudes towards technology use. Senior project staff conducted interviews with administrators at each participating school at the beginning of the study, and follow-up conversations happened on an ad hoc basis throughout the project as needed. There interviews provided the background information on schools and provided much needed context for the analysis of data collected by other means.

\section{Data Analysis}

Qualitative data from teacher logs were coded using a grounded coding approach by at least two researchers [31, 
32], while quantitative data were averaged across each academic year to provide an overall frequency of use statistic for each teacher. Results from these analyses were incorporated into narrative summaries, describing whether the classroom was teacher-centered or student-centered, how often each teacher and their students used the IWB, for what purposes, and the costs and benefits of that use. Data from other sources were used to provide a more comprehensive view of each teacher's practice, and to add depth to the narratives. Summaries of data, and interpretive narratives, were "member checked," that is, presented to the teachers, allowing them to verify or correct the accuracy of our summaries.

\section{RESULTS}

\section{A. IWB Integration}

Participating teachers came from technology-rich schools, with access to IWBs, laptop computers, the Internet, and various other hardware and software. Log data, teacher questionnaires, and classroom observations confirmed that, despite similar access to technology, there was significant variation in the extent to which teachers adopted and integrated these tools. Teachers in our sample fell along a continuum - from the technologically savvy early adopters to the technologically resistant non-users. The majority of our teachers fell between these two extremes, using the IWB sometimes, for well-defined purposes, and with varied success.

Drawing on data from teacher logs, questionnaires, focus groups, classroom observations, and vignettes, we classified teachers based on the frequency with which they used the IWB, the extent to which they used the IWB to support student understanding of science concepts (the quality of use), and the ways in which they used the IWB to bring other tools into the classroom (see Table 1). We explore these patterns of integration in the coming sections, highlighting the practice of representative teachers.

Early adopters: We identified 4 teachers (14\% of the sample) as "early adopters." In addition to log data indicating frequent and varied use of the IWB, classroom observations and focus group discussions revealed that these teachers were passionate about technology in general. They enthusiastically incorporated technology, encouraged their students to experiment, and thoughtfully considered the best ways to integrate technology so as to meet curricular goals. Though many teachers in the sample used the IWB regularly, what set the early adopters apart from their peers is the persistence with which they sought new ways to incorporate it into their teaching, and integrate it with other technologies. As verified in both self-report measures and in classroom observations, these teachers integrated multimedia into their presentations, linked to outside resources and Internet sites, annotated slides, and used the board as a focal point to foster deep science discussion.

One teacher, whom we call "Eric," epitomizes the early adopter profile. 'A veteran teacher at "Private Academy," Eric actively sought out new technology. He often used non-traditional technologies in the classroom, including RSS feeds, wikis, and podcasts. His students completed high-tech labs using probeware, navigated the Web to access additional content, used clickers to complete in-

\footnotetext{
${ }^{1}$ All names have been changed to protect teachers' identities.
}

TABLE I.

SUMMARY OF IWB ADOPTION AND INTEGRATION CRITERIA

\begin{tabular}{|c|c|c|c|}
\hline & Frequency of Use & $\begin{array}{l}\text { Support Scientific } \\
\text { Understanding }\end{array}$ & $\begin{array}{c}\text { Facilitate Inte- } \\
\text { gration of } \\
\text { Technology }\end{array}$ \\
\hline $\begin{array}{l}\text { Early } \\
\text { Adopter }\end{array}$ & $\begin{array}{l}\text { Teacher reports } \\
\text { using the IWB in } \\
\text { greater than } 75 \% \text { of } \\
\text { log periods. Obser- } \\
\text { vations and focus } \\
\text { group data support } \\
\text { regular use. }\end{array}$ & $\begin{array}{l}\text { Teacher uses the } \\
\text { IWB as lecture aid, } \\
\text { but also as a tool to } \\
\text { facilitate discussion } \\
\text { and active student } \\
\text { participation. } \\
\text { Teacher frequently } \\
\text { uses the interactive } \\
\text { features of the } \\
\text { IWB. }\end{array}$ & $\begin{array}{l}\text { Teacher uses the } \\
\text { IWB in conjunc- } \\
\text { tion with multi- } \\
\text { ple other tools, } \\
\text { and also incor- } \\
\text { porate Web- } \\
\text { based resources. }\end{array}$ \\
\hline $\begin{array}{l}\text { Typical } \\
\text { User }\end{array}$ & $\begin{array}{l}\text { Teacher reports } \\
\text { using the IWB in } \\
\text { greater than } 50 \% \text { of } \\
\text { log periods, but } \\
\text { less than } 75 \% \text {. } \\
\text { Observations and } \\
\text { focus group data } \\
\text { support regular use. }\end{array}$ & $\begin{array}{l}\text { Teacher uses the } \\
\text { IWB as a tool to } \\
\text { support teacher } \\
\text { lecture. Interactive } \\
\text { features of the IWB } \\
\text { are not regularly } \\
\text { used. }\end{array}$ & $\begin{array}{l}\text { Teacher uses the } \\
\text { IWB in conjunc- } \\
\text { tion with a few } \\
\text { other tools to } \\
\text { present lecture } \\
\text { material. }\end{array}$ \\
\hline $\begin{array}{l}\text { Resistant } \\
\text { User }\end{array}$ & $\begin{array}{l}\text { Teacher reports } \\
\text { using the IWB in } \\
\text { less than } 50 \% \text { of all } \\
\text { log periods. Obser- } \\
\text { vations and focus } \\
\text { group data support } \\
\text { infrequent use. }\end{array}$ & $\begin{array}{l}\text { Teacher infrequent- } \\
\text { ly uses the IWB, } \\
\text { neither for lecture } \\
\text { nor to support } \\
\text { student-centered } \\
\text { learning. }\end{array}$ & $\begin{array}{l}\text { Teacher makes } \\
\text { little or no effort } \\
\text { to incorporate } \\
\text { other tools. }\end{array}$ \\
\hline
\end{tabular}

class quizzes, and communicated with one another via email and the school's Intranet. In his teacher logs, Eric rarely mentioned limitations associated with using technology in the classroom. According to focus group discussions, he was viewed as a leader amongst his peers, regularly providing information and guidance on emerging technologies.

The IWB fit seamlessly into Eric's existing pedagogical style. Even prior to the introduction of the IWB, his classes were a mix of teacher lecture and student exploration. The IWB allowed him to expand the possibilities for student-directed learning. Vignettes illustrate that students often took the reins to "show what they know," utilizing software, such as Apple's GarageBand, in conjunction with the IWB. The responsibility shifted from teacher to student as students worked with each other to create products that could then be shared via the IWB.

George, another early adopter, was a novice teacher at "Large Urban High." He was a new teacher in the third and final year of the study, and, like Eric, was also in the initial stages of IWB adoption and integration. George's pedagogical style valued student involvement and active learning, and the IWB helped him to involve students in interesting ways. Like Eric, George was comfortable experimenting with technology, and frequently searched for ways to improve the classroom experience.

In one vignette, George described how his students used Excel, a wireless keyboard, and the IWB to explore Mendelian genetics and probability. The keyboard was passed around the room, allowing students to input their experimental data directly and to see the results in real time on the IWB. In contrast to his traditional lesson, in which he would use PowerPoint and a teacher-centered approach, this method "allowed students to observe their own traits and evaluate the concept of probability in real time." He reported high student engagement and motiva- 
PAPER

INTERACTIVE WhiteboARd USE IN High-TECH SCIENCE ClASSROOMS: PATTERNS OF INTEGRATION

tion, with students "enjoying the experience enough to tell their friends about it."

For these early adopters, the IWB quickly became more than just a tool to project static content. The IWB enabled them to bring in other technologies in innovative ways. It allowed them to give their students an active role in daily lessons, and to be more engaged with the science content. These teachers were flexible enough in their teaching style to identify ways in which the IWB could improve the quality of teaching and learning, and to take steps to integrate it in those ways.

Typical users: Based on both self-report data, including focus groups, questionnaires, and logs, along with observations of classroom activities, most teachers in our study did not meet our early adopter criteria. The 21 teachers ( $75 \%$ of the sample) who occupy the middle section of the continuum are referred to here as typical users. They ranged in experience from novice to veteran teachers, and represented all three subject areas (chemistry, biology, and physics). Though our typical users used the IWB regularly (in $50 \%$ or more of all $\log$ periods), with many teachers reporting using it in $75 \%$ or more of log periods, log reports revealed that they used it primarily as a tool to prepare and present lecture materials, with almost no student interaction.

Many of the teachers in this group used the IWB exclusively for presenting content, without integrating any of the features that set the IWB apart from traditional whiteboards. Some, however, did occasionally take advantage of some of the affordances specific to the IWB. The most commonly used advanced feature amongst this group was the ability to integrate multimedia into presentations, with several teachers reporting this type of use in their teacher logs. Compared to the early adopters, however, their use was limited and brief. Oftentimes they used multimedia for a specific lesson, but did not generalize this type of use across the curriculum.

Colin, a typical user in many respects, represents an interesting case because his integration trajectory spanned the range of typical use, starting out towards the low-use end of the continuum and moving steadily over time towards the high-use end. In the second year of the study, Colin was a first-year teacher at "Rural High," though he had previous teaching experience at another school. He approached new technology cautiously, and his use was often tentative and constrained. When he chose to use technology, it was to accomplish very specific tasks, and with little exploration of the possibilities of the technology. Log data revealed that his most frequent use was of well-established tools, such as Word and e-mail. Students in his class used technology sparingly, for tasks such as writing up lab reports or checking the class website.

Colin's use of the IWB changed over the course of the study. At first, he used the IWB as a substitute for the traditional whiteboard. According to comments made in a focus group, the motivation for this use came from convenience; the IWB was centrally located in the classroom, making it difficult not to use the technology. Slowly, however, Colin's attitude towards its use began to shift. He noticed that using the IWB enabled him to carefully prepare lessons ahead of time, crafting neat yet flexible presentations. His use of the IWB was still basic at this point - a means of presenting lectures - but, over the course of his first year with the IWB, his perception shifted away from viewing it as an inconvenience.

In Colin's second year of IWB use, as he became more comfortable and familiar with the technology, instances arose where he had the opportunity to use the IWB in innovative ways to meet curricular goals. One of the first indications of this change was a vignette Colin submitted in which he discussed integrating a software program into an IWB-based lesson. The technology went from being a convenient tool for presenting lecture materials, to a technological innovation that enabled Colin to improve his students' understanding.

For many other typical users, however, there was no such change in patterns of use over the course of the threeyear study. Teachers, both novice and experienced, from highly supportive schools and unsupportive schools, in all different subject areas, failed to utilize the advanced features of the IWB. These teachers used the IWB frequently, sometimes daily, but without any further integration or change in pedagogy.

Resistant adopters: Three teachers (11\% of the sample) were coded as resistant adopters. They used the IWB infrequently (in less than $50 \%$ of log periods), and, compared to our typical users, these teachers were less likely to use the IWB for projecting content to students. They were more likely to report difficulties with the IWB in their teacher logs and in focus groups, from minor practical issues, such as placement of cords and aligning the IWB, to larger technical issues, including issues with software and hardware. Log data detailing frequency of tool use suggests that these teachers were also resistant to other new technologies, preferring to use established tools like Word, PowerPoint and e-mail.

One resistant, Sarah, was a first year teacher at "Rural High," though she had previously taught at a large urban school where technology use was heavily encouraged. The frequency with which she used the IWB, reported in $38 \%$ of log periods, was low compared to her colleagues. However, when asked to report the potential benefits of the IWB on the teacher questionnaire, she noted "more interactive PowerPoint presentations" and "animations, videos and images" as benefits. Her awareness of the potential benefits did not translate into use in the classroom.

Another low-use teacher from the same school justified her lack of use by saying that "writing on the board is just as easy," and noting that she did not want to become dependent on the IWB in the event that technical issues arose. Log data revealed that on most weeks this teacher did not use the IWB. On the infrequent occasion in which she did use it, however, she did so in interesting ways. For example, in one class, she wrote of how students used the board to draw pictures of cell function, and in another the class used the board to play Jeopardy. This teacher was coded as a resistant adopter due to her low frequency of use and expressed negative perceptions regarding the use of technology. Yet, in the very rare instance in which she used technology, she was one of the few teachers in our sample who involved her students in using the IWB. Her profile, like that of Colin, reminds us that teachers do not fall neatly into one category or another, and they may move across the continuum over time or with changing circumstances. 
PAPER

INTERACTIVE WhiteboARd USE IN High-TECH SCIENCE ClASSROOMS: PATTERNS OF INTEGRATION

\section{B. Barriers to Integration}

Internal factors: For some of the low-use teachers, the main barrier to integration appeared to be a lack of knowledge regarding the features and functions of the IWB. Colin, for example, didn't at first understand how to use the IWB, or what functionality was available to him. This lack of knowledge led him to believe that the IWB would be more of a nuisance than a benefit to him and his students. Teachers with limited knowledge of the IWB often focused on the technical and logistical drawbacks of the IWB, such as the possibility for the software to crash or the need to reposition the board, as reasons to avoid technology.

Many teachers, even those with moderate to high use, spoke of the lack of professional development experiences that would provide them with the skills and knowledge necessary to use the IWB to effectively teach science. Forty percent of teachers in the study reported that they had to seek out their own professional development experiences, while another $15 \%$ said their schools encouraged training but did not plan or set up training opportunities for teachers. In focus group discussions, teachers spoke of an interest in not only learning how to use the features of the IWB, but how to best integrate it into their practice.

For other teachers, even those who sought to use technology in their classrooms (typical users), log and observation data suggest that their preferred pedagogical style seemed to get in the way of effective technology integration. For those that favored a frontal style, changing the classroom to be more student-centered via the use of interactive presentations, student-led discussion, and peerto-peer collaboration was not an attractive option. These teachers struggled to maintain their current pedagogy in the face of changing technology, choosing to use only the most basic tools for everyday tasks (e.g., using Excel only to calculate grades without any plan for student use), and avoiding using technology as a way to teach science.

External factors: For some teachers, the school environment appeared to hinder successful integration of the IWB. Though all schools were considered "technologyrich," they differed greatly from one another in the quality of their resources, the infrastructure necessary to support use, and the level of detail in their technology plans. A few schools had staff dedicated to assisting teachers and students with new technology, detailed technology plans, and planned professional development opportunities, while other schools had vague or no technology directives, part-time technology staff, and no in-house professional development. In two of the schools, students had laptops of their own, while students in the other four schools used communal laptops. All schools had Internet access, five with wireless connectivity and one with Ethernet ports.

Eric, the early adopter, came from a school culture that placed a high value on technology. Administrators at his school required teachers to attend school-sponsored training sessions, individual teachers mentored their colleagues, and technology was pervasive throughout the school. Though his colleagues may not have been as technologically savvy as Eric, each of them used technology regularly as part of the curriculum. There was a culture of use at the school, and administrators made it clear that teachers were expected to adhere to a detailed plan of technology integration.
Both Colin and two of the low-use teachers described earlier came from a small, rural high school. Despite its enrollment of only 400 students, the school had three full time technical staff. They also had a fully elaborated technology plan, that was pedagogically informed and realistic. In terms of technology access, teachers had enough laptops for a 1-to-1 ratio. In this case, despite adequate access and support, many teachers did not regularly integrate technology. Discussions with teachers at this school suggested that other factors, including tensions between teachers and administrators, were at play. So, while a school's technology culture may help or hinder teachers' technology use, there is not always a clear and direct relationship between the two.

\section{DISCUSSION}

Interactive whiteboards have the potential to positively influence teaching and learning by enabling teachers to easily and efficiently create flexible multimedia presentations, increase student engagement and motivation, and enhance achievement $[6,7,11]$. There is also evidence to suggest that the IWB offers subject-specific benefits, helping students to gain a deeper understanding of science content and practices $[15,19]$. The extent to which this potential has been realized in practice, however, is unclear. The current study aimed to fill this gap by exploring patterns of IWB integration for a diverse set of teachers, and internal and external barriers to integration.

Our results suggest that incomplete IWB integration whereby teachers use the IWB infrequently, without encouraging student interaction, and without taking advantage of the IWB's interactive features - is not sufficient to reap the benefits reported in the literature. The majority of teachers in our study used the IWB in a limited capacity, to present static PowerPoint slides in a manner that often reinforced, rather than transformed, existing pedagogy. Not only did resistant and typical teachers use technology less frequently than their early adopter peers, but they also did not realize the full potential of the technology in terms of quality of use.

For our early adopters, it was the way in which they integrated the IWB, more than frequency of use, that distinguished them from typical users. Eric, our prototypical "early adopter," used the IWB to bring in multimedia resources, allowed students to take control of the classroom via the board to share their knowledge, and skillfully linked the IWB and other tools to improve the student experience. Because he was confident in his content, pedagogical and technology knowledge, he found it easy to creatively incorporate the IWB to support and amplify key aspects of his pedagogy. Students in classrooms like Eric's reaped the benefits of their teachers' savvy use. They had the opportunity to access real-life science data, bringing the classroom experience to life. The IWB also served as an interactive joint point of reference, enabling students to focus on the content, interact with teacher and peers, and engage in deep scientific thinking. Prior research has shown that use of an IWB produced feelings of participation on the part of the student, even when they were not actively manipulating the board [19].

Defining a teacher as an early adopter or as a typical user is perhaps too simplistic. Even in the relatively short time span of the current study, we found significant movement along the continuum for some teachers. Colin 
PAPER

INTERACTIVE WhiteboARd USE IN High-TECH SCIENCE ClASSROOMS: PATTERNS OF INTEGRATION

is an excellent example. At the start of the study, Colin was on the low end of the continuum, only using the IWB because it would be inconvenient not to use it. He was not aware of the unique affordances of the IWB, and therefore found it difficult to think about how to engage his students with the technology. Gradually, as he gained experience using the IWB as a presentation tool, he began to expand his use, and, by the end of the study, Colin's practice began to look more like that of the early adopters.

Colin's case highlights the fact that integrating technology so that it supports pedagogy takes time for the average teacher, and other researchers have described similar evolutions [33]. These cases suggest that with the right training experiences and a supportive school culture, "typical" teachers can become proficient with technology. High quality professional development experiences that afford teachers hands-on experiences with the IWB, and guidance in how the IWB may be used to support their teaching, are integral to success.

A small number of the teachers in our sample populated the low end of the continuum, using the IWB infrequently and, oftentimes, reluctantly. For many of these resistant teachers, this pattern held true for technology other than the IWB, suggesting a negative attitude towards technology in general, rather than a particular feeling towards the IWB. Unlike for the early adopters and the typical users, technology tended to feel like an added stressor for the resistant user. For many, the sudden influx of technology in their classrooms was overwhelming, and, without strategies in place to deal with the technology, they often chose to simply not use the new tools.

Teachers in the sample noted a variety of barriers to integration, some associated with their own personal preferences or knowledge, some related to the IWB itself, and others influenced by the school culture. Oftentimes it was not easy to disambiguate these factors, and it is likely that multiple factors are at work in any given case. We discuss these barriers to successful integration in turn, and conclude with a discussion of possible professional development strategies designed to overcome them.

Teachers' content knowledge and pedagogical knowledge can sometimes be at odds with effective technology integration. Results from the current research, as well as the prior literature, suggest that introducing new technology into the classroom does not typically lead to immediate pedagogical change; the process is often slow and evolutionary [19]. The introduction of new technology can be viewed as a disruption, and teachers must learn to reconstruct the equilibrium between content knowledge, pedagogy, and technological knowledge in order to effectively integrate any new tool [34]. Furthermore, some teachers in our study had very traditional pedagogical views, which have been shown to be incompatible with technology adoption and integration [35].

However, even teachers who were open to change faced challenges. Teachers in the current study were working in high-tech schools, with access to a wide range of technology, so lack of tools, which is a major problem especially in countries outside of Europe and the United States [36]. Some teachers in our study were overwhelmed by the preponderance of technology available to them, unable to find sufficient time to investigate tools like the IWB and determine if and how they might be useful in the classroom. In fact, the most commonly reported reason for not using technology was a lack of time, a finding that has been supported elsewhere $[20,30]$. Coupled with a lack of appropriate training, another major impediment cited in Cuban and colleagues' work, it is not surprising that some teachers chose to simply not use the technology at all.

Others failed to integrate the IWB because of a lack of technological skill. For some teachers in our sample, this was the major barrier to integration of the IWB and other tools. Many teachers who struggled with the technical aspects reported a lack of high-quality professional development experiences. Teachers who came from schools that did offer these experiences were less likely to cite technological issues as reasons for non-use. Case study research conducted by reference [37] suggests that in order to use the full range of IWB capabilities, teachers require training about effective instructional strategies.

The IWB, like any other tool, comes with its own set of practical and logistical difficulties. Problems with positioning and adequate visibility of the board were quite common complaints amongst our sample, and have also been cited in the literature [3, 38]. Early adopters also noted these issues, but they were less likely to avoid the technology because of them. Some of the lower use teachers, especially those who were not as confident in their technological skill, were more likely to be deterred by such difficulties. Coupled with a lack of technical support, minor practical and logistical concerns sometimes became major barriers to effective integration.

Another common source of difficulty is the school culture, which led even some skilled and confident teachers to avoid integrating the IWB. Teachers in our sample came from six different schools, and each school had its own unique technology culture. Some schools had very detailed technology plans, skilled support staff, and a supportive administration, while others did not. Eric, our early adopter, came from a school that placed a high value on technology, and had a culture that was very supportive of advanced technology use. Though not all of his peers were early adopters, they all utilized technology in support of the curriculum. Colin and some of the resistant users taught in a very different setting. Though their school had a detailed technology plan in place and support staff available, there was a tension between administrators and staff that reduced the teachers' desire to expend effort on technology integration. We found that for teachers in our sample, school culture seemed to make it easier or more difficult for teachers to integrate technology, but, in the end, other factors also played an important role.

Teaching is a demanding occupation, one whose complexity that reference [27] compares to a physician in an emergency room after a natural disaster. Each day, teachers are faced with a classroom of diverse learners, with varying needs, and are expected to teach in such a way as to reach all students. Technology, in many cases, only adds to the complexity, providing teachers with another variable to be mindful of. High quality professional development opportunities are necessary to provide teachers with the knowledge, skills, self-confidence, and motivation to adopt and integrate new technology so as to meet the needs of their students.

Research suggests that providing teachers with opportunities to tinker with technology and to watch skilled colleagues utilize it may improve their uptake $[6,25,33]$. Reference [6] suggests that teachers be allowed to "ex- 
plore broader pedagogic issues from the outset" ("Conclusions and Directions," para. 8), rather than focusing on specific technical skills. Reference [22] notes the importance of the disciplinary community in professional development. For science teachers, professional development experiences should showcase how the IWB can be used to support teaching and learning in science. It is through this type of experience that teachers will begin to gain the skills necessary to use the IWB as a tool for expanding and transforming the science classroom.

There is evidence to suggest that peer coaching has an important role in improving teachers' facility with the IWB, and with technology integration in general. Teachers in reference's [8] work found support teachers (who they referred to as "missioners") to be of the utmost importance, helping less savvy teachers move beyond using the board as a tool for efficiency. Learning communities within schools have been shown to be powerful resources for teachers [39], providing "just in time" learning of a kind particularly useful to science teachers in a fastmoving technology environment [40, 41]. Within a school, early adopters could assist typical and resistant users in learning about technology and how it might be used to meet curricular goals.

\section{A. Conclusion}

The early literature's promise of the IWB's ability to transform the classroom has not been fully realized. Despite widespread access, many teachers are simply not using the advanced features of the IWB - those features that set it apart from a traditional whiteboard and projector - and are therefore not reaping the rewards. Early adopters are relatively rare, and, more often than not, new technology reinforces teachers' existing pedagogical style, rather than altering it in any significant way [20]. For the IWB, "it is only when used to extend and transform learning that they justify their cost..." [38, para. 1]. Results from the current study highlight a variety of factors that influence teacher adoption and integration. Additional research, with a focus on high-quality professional development experiences, is needed to define ways in which teachers and students may overcome barriers in order to foster optimal IWB use.

\section{REFERENCES}

[1] McIntyre-Brown, C. (2011). Understanding the Next Wave of Technology Innovation in Education: UK.

[2] Robertson, C., \& Green, T. (2012). Interactive whiteboards on the move! TechTrends, 56, 15-17. http://dx.doi.org/10.1007/s11528012-0607-z

[3] Hall, I., \& Higgins, S. (2005). Primary school students' perceptions of interactive whiteboards. Journal of Computer Assisted Learning, $\quad 21, \quad 102-117 . \quad$ http://dx.doi.org/10.1111/j.13652729.2005.00118.x

[4] Beeland, W. (2002). Student engagement, visual learning and technology: Can interactive whiteboards help? Retrieved from http://teach.valdosta.edu/are/Artmanscrpt/vollnol/ beeland_am.pdf

[5] Glover, D., \& Miller, D. (2001). Running with technology: The pedagogic impact of the large-scale introduction of interactive whiteboards in one secondary school. Journal of Information Technology for Teacher Education, 10, 257-278. http://dx.doi.org/10.1080/14759390100200115

[6] Levy, P. (2002). Interactive whiteboards in learning and teaching in two Sheffield schools: A developmental study. Retrieved from http://dis.shef.ac.uk/eirg/projects/wboards.htm
[7] Smith, H., Higgins, S., Wall, K., \& Miller, J. (2005). Interactive whiteboards: boon or bandwagon? A critical review of the literature. Journal of Computer Assisted Learning, 21, 91-101. http://dx.doi.org/10.1111/j.1365-2729.2005.00117.x

[8] Miller, D., \& Glover, D. (2002). The interactive whiteboard as a force for pedagogic change: The experience of five elementary schools in an English education authority. Information Technology in Childhood Education Annual, 1, 5-19.

[9] Bell, M. (2001). Update to survey of use of interactive electronic whiteboard in instruction. Retrieved from http://www.shsu.edu/ lis_mah/documents/updateboardindex.htm

[10] Schut, C. (2007). Student perceptions of interactive whiteboards in a biology classroom (Master's thesis). Retrieved from http://rave.ohiolink.edu/etdc/view?acc_num= cedar1202225704

[11] Wall, K., Higgins, S., \& Smith, H. (2005). 'The visual helps me understand the complicated things': Pupil views of teaching and learning with interactive whiteboards. British Journal of Educational Technology, 36, 851-867. http://dx.doi.org/10.1111/j.14678535.2005.00508.x

[12] Higgins, S., Beauchamp, G., \& Miller, D. (2007). Reviewing the literature on interactive whiteboards. Learning, Media and Technology, 32, 213-225. $\quad$ http://dx.doi.org/10.1080/174398807 01511040

[13] Gillen, J., Littleton, K., Twiner, A., Staarman, J., \& Mercer, M. (2008). Using the interactive whiteboard to resource continuity and support multimodal teaching in a primary science classroom. Journal of Computer Assisted Learning, 24, 348-358. http://dx.doi.org/10.1111/j.1365-2729.2007.00269.x

[14] Lopez, O. (2010). The Digital Learning Classroom: Improving English Language Learners' academic success in mathematics and reading using interactive whiteboard technology. Computers \& Education, 54, 901-915. http://dx.doi.org/10.1016/j.compedu. 2009.09.019

[15] Murcia, K., \& Sheffield, R. (2010). Talking about science in interactive whiteboard classrooms. Australasian Journal of Educational Technology, 26, 417-431.

[16] Schmid, E. (2008). Potential pedagogical benefits and drawbacks of multimedia use in the English language classroom equipped with interactive whiteboard technology. Computers \& Education, 51, 1553-1568. http://dx.doi.org/10.1016/j.compedu.2008.02.005

[17] Torff, B., \& Tirotta, R. (2010). Interactive whiteboards produce small gains in elementary students' self-reported motivation in mathematics. Computers \& Education, 54, 379-383. http://dx.doi.org/10.1016/j.compedu.2009.08.019

[18] Scott, P., Mortimer, E., \& Aguiar, O. (2006). The tension between authoritative and dialogic discourse: A fundamental characteristic of meaning making interactions in high school science lessons. Science Education, 90, 605-631. http://dx.doi.org/10.1002/ sce. 20131

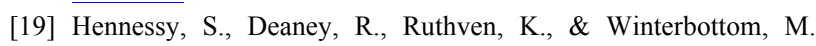
(2007). Pedagogical strategies for using the interactive whiteboard to foster learning participation in school science. Learning, Media and Technology, 32, 283-301. http://dx.doi.org/10.1080/ 17439880701511131

[20] Cuban, L., Kirkpatrick, H., \& Peck, C. (2001). High access and low use of technologies in high school classrooms: Explaining an apparent paradox. American Educational Research Journal, 38, 813-834. http://dx.doi.org/10.3102/00028312038004813

[21] Kozma, R. (2003). Technology and classroom practices: An international study. Journal of Research on Technology in Education, 36, 1-14. http://dx.doi.org/10.1080/15391523.2003.10782399

[22] Klieger, A., Ben-Hur, Y., \& Bar-Yossef, N. (2010). Integrating laptop computers into classroom: Attitudes, needs, and professional development of science teachers - a case study. Journal of Science Education and Technology, 19, 187-198. http://dx.doi.org/10.1007/s10956-009-9191-1

[23] Zhao, Y., Pugh, K., Sheldon, S., \& Byers, J. (2002). Conditions for classroom technology innovations. Teachers College Record, 104, 482-515. http://dx.doi.org/10.1111/1467-9620.00170

[24] Drayton, B., Falk, J., Stroud, R., Hobbs, K., \& Hammerman, J. (2010). After installation: Ubiquitous computing and high school science in three experienced high-technology schools. The Journal of Technology, Learning, and Assessment, 9, 1-57. 
PAPER

INTERACTIVE WhiteboARd USE IN High-TeCH SCIENCE ClassRoOMS: PATTERNS OF INTEGRATION

[25] Ertmer, P., \& Ottenbreit-Leftwich, A. (2010). Teacher technology change: How knowledge, confidence, beliefs, and culture intersect. Journal of Research on Technology in Education, 42, 255284. http://dx.doi.org/10.1080/15391523.2010.10782551

[26] Koehler, M., \& Mishra, P. (2008). Introducing TCPK. In Handbook of technological pedagogical content knowledge (TPCK) for educators (pp. 3-29). New York, NY: Taylor \& Francis.

[27] Shulman, L. (1987). The wisdom of practice: Managing complexity in medicine and teaching. In D. Berliner \& B. Rosenshine (Eds.), Talks to teachers: A festschrift for N. L. Gage (pp. 369387). New York, NY: Random House.

[28] Mishra, P., \& Koehler, M. (2006). Technological pedagogical content knowledge: A framework for teacher knowledge. Teachers College Record, 108, 1017-1054. http://dx.doi.org/10.1111/ j.1467-9620.2006.00684.x

[29] Wozney, L., Venkatesh, V., \& Abrami, P. (2006). Implementing computer technologies: Teachers' perceptions and practices. Journal of Technology and Teacher Education, 14, 173-207.

[30] Bauer, J., \& Kenton, J. (2005). Toward technology integration in the schools: Why isn't it happening? Journal of Technology and Teacher Education, 13, 519-546.

[31] Glaser, B., \& Strauss, A. (1967). The Discovery of Grounded Theory: Strategies for Qualitative Research. Chicago: Aldine.

[32] Strauss, A., \& Corbin, J. (1998). Basics of Qualitative Research: Techniques and Procedures for Developing Grounded Theory $\left(2^{\text {nd }}\right.$ ed.). Newbury Park, CA: Sage.

[33] Latham, P. (2002). Teaching and learning primary mathematics: The impact of interactive whiteboards. London, UK: BEAM Education.

[34] Slay, H., Sieborger, I., \& Hodgkinson-Williams, C. (2008). Interactive whiteboards: Real beauty or just "lipstick"? Computers \& Education, 51, 1321-1341. http://dx.doi.org/10.1016/j.compedu. 2007.12.006

[35] Hermans, R., Tondeur, J., van Braak, J., \& Valcke, M. (2008). The impact of primary school teachers' educational beliefs on the classroom use of computers. Computers \& Education, 51, 14991509. http://dx.doi.org/10.1016/j.compedu.2008.02.001
[36] Jang, S., \& Tsai, M. (2012). Reasons for using or not using interactive whiteboards: Perspectives of Taiwanese elementary mathematics and science teachers. Australasian Journal of Educational Technology, 28, 1451-1465.

[37] Turel, Y., \& Johnson, T. (2012). Teachers' belief and use of interactive whiteboards for teaching and learning. Educational Technology \& Society, 15, 381-394.

[38] Becta (2003). What the research says about interactive whiteboards. Coventry, UK: Becta.

[39] National Commission on Teaching and America's Future (2010). STEM Teachers in Professional Learning Communities: A Knowledge Synthesis. Retrieved from https://www.nctaf.org/documents/STEMTeachersInProfessionalLe arningCommunities.AKnowledgeSynthesis.pdf

[40] Drayton, B., \& Falk, J. (2006). Dimensions that shape teacherscientist collaborations for teacher enhancement. Science Education, 90, 734-761. http://dx.doi.org/10.1002/sce.20138

[41] Huberman, M. (1993). The model of the independent artisan in teachers' professional relations. In J.W. Little and M.W. McLaughlin (Eds.), Teachers' work: Individuals, colleagues, contexts. New York, NY: Teachers College Press.

\section{AUTHORS}

R. Stroud is with TERC, Cambridge, MA 02140 USA. (e-mail: rena_stroud@terc.edu).

B. Drayton is with TERC, Cambridge, MA 02140 USA (e-mail: brian_drayton@terc.edu).

K. Hobbs is with TERC, Cambridge, MA 02140 USA (e-mail: kathryn_hobbs@terc.edu).

J. Falk is with TERC, Cambridge, MA 02140 USA (email: joni_falk@terc.edu).

This work was supported in part by the National Science Foundation under Grant 0455795. Submitted 19 August 2014. Published as resubmitted by the authors 15 October 2014 . 